\title{
Early changes in coagulation following a paracetamol overdose and a controlled trial of fresh frozen plasma therapy
}

\author{
B. G. GAZZARD, J. M. HENDERSON, AND ROGER WILLIAMS
}

From the Liver Unit, King's College Hospital and Medical School, London

SUMMARY Early changes in coagulation were found in patients following a paracetamol overdose. Low levels of clotting factors II, V and VII were present within 24 hours of the overdose. As the levels of factor II correlated with plasma fibrinogen values at this time, it is possible that they were consumed in the process of intravascular coagulation, although this was not supported by the presence of raised titres of fibrin degradation products. The prothrombin time ratio was greater than $2 \cdot 2$ within 30 hours of ingestion of the overdose in all patients who eventually died, whereas it was less than this in those developing only moderate liver damage. The administration of fresh frozen plasma to patients did appear to reduce the maximum abnormality of the prothrombin time ratio, which was significantly less three days after the overdose in the group receiving fresh frozen plasma. However, the coagulation disturbance was of short duration, and the prothrombin time ratio had also returned to normal within one week of the overdose in the control patients, and the administration of fresh frozen plasma did not appear to reduce the morbidity or mortality in the treated patients.

Paracetamol is frequently taken as an overdose in suicidal attempts, and hepatic damage of all grades of severity, from minor to fulminant hepatic failure, may result (Prescott, Wright, Roscoe, and Brown, 1971). In the latter group bleeding is often a major problem and is not infrequently the direct cause of death. It is thought to be due in part to low levels of clotting factors resulting both from impaired hepatic synthesis and increased consumption from intravascular coagulation (Rake, Flute, Shilkin, Lewis, Winch, and Williams, 1971). To replace this synthetic deficiency we have advocated the regular use of fresh frozen plasma (FFP), although controlled evidence of its value was lacking.

In this paper we describe detailed studies, including individual clotting factor assays, in 66 patients seen shortly after a paracetamol overdose, together with the results of a controlled trial of FFP in those patients in whom a severe coagulation disturbance subsequently developed.

Received for publication 9 May 1975.

\section{Patients and Methods}

In 66 patients, the prothrombin time was estimated within $30 \mathrm{hr}$ of the overdose and in 14 of them individual clotting factor levels were also determined. Standard liver function tests were carried out at this time and then daily. Those patients who developed a plasma bilirubin concentration of more than $69 \mu \mathrm{mol} / 1$ were classified as having severe hepatic damage, as we have previously shown that these are the patients in whom encephalopathy and other signs of fulminant hepatic failure are most likely to occur (Clark, Borirakchanyavat, Gazzard, Rake, Shilkin, Flute, and Williams, 1973b). Indeed, the nine deaths in the series were all from this group. Those patients in whom the maximum plasma bilirubin recorded was less than $69 \mu \mathrm{mol} / 1$ were grouped together as having moderate hepatic damage.

The controlled trial was carried out in 20 consecutive patients who developed a severe coagulation defect, as shown by a prothrombin time ratio of 
more than $2 \cdot 2$. Eight of these patients who had been seen within $24 \mathrm{hr}$ of the overdose formed part of the series referred to above, the remaining cases being admitted after $48 \mathrm{hr}$ or more. The 20 patients were randomly allocated by a system of sealed envelopes either to supportive therapy only (group A) or to treatment with FFP ( $300 \mathrm{ml}$ every six hr) until the prothrombin time ratio had fallen to less than 1.4 (group B). Seven of the patients in group B were first seen $48 \mathrm{hr}$ or more after the overdose. If at any time the prothrombin time ratio rose to 7.0 or more the dose of FFP was increased to $600 \mathrm{ml}$, this also being given to the group A 'control' patients.

\section{METHODS}

The prothrombin time, factor II levels (two-stage technique), factor $\mathrm{V}$ levels (one-stage technique) and factor VII levels (one-stage technique using a patient factor-VII-deficient plasma) were determined by standard methods (Denson, 1972). Fibrinogen was estimated gravimetrically (Denson, 1972) and fibrinogen degradation products by the tanned red cell haemagglutination inhibition technique (Merskey, Lalezari, and Johnson, 1969).

\section{Results}

In 36 of the 66 patients, the prothrombin time ratio was already abnormal (> 1.4) $30 \mathrm{hr}$ after the overdose (fig 1). The degree of abnormality provided a good index of the hepatic damage that subsequently appeared. All the patients who developed severe

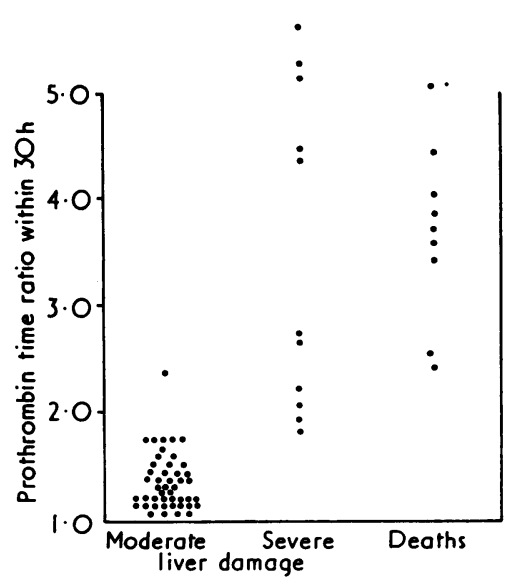

Fig 1 The prothrombin time ratio measured within $30 \mathrm{hr}$ of the paracetamol overdose in the patients who subsequently developed either moderate or severe liver damage. The deaths, all in the severe group, are shown separately. hepatic damage had a prothrombin time ratio of more than 1.8 at this time, and with one exception it was less than this in the patients developing moderate liver damage only. No patient with a normal prothrombin time ratio at $30 \mathrm{hr}$ subsequently developed evidence of liver failure. However, the prothrombin time ratio did not identify which of the patients in the group with severe hepatic damage would die. Serum aspartate aminotransferase levels and the serum bilirubin levels were also always raised within $30 \mathrm{hr}$ of ingestion (mean $2100 \mathrm{iu} / 1$ and $71 \mathrm{umol} / \mathrm{l}$ ) in nine patients who died, but these levels were not significantly different from those in others who developed severe hepatic necrosis but did not die.

Levels of factor II measured in four patients within $12 \mathrm{hr}$ of the overdose were normal, although in three of these the factor $\mathrm{V}$ levels were reduced to between 50 and $60 \%$ of normal. However, by $24 \mathrm{hr}$ the levels of factor II, V and VII were considerably reduced in many of the patients studied (fig 2), the lowest levels being recorded in those who subsequently developed severe hepatic damage. Plasma fibrinogen levels within the first $24 \mathrm{hr}$ varied widely: four were slightly reduced at $150 \mathrm{mg} / 100 \mathrm{ml}$ (the lower limit of normal for our laboratory is $200 \mathrm{mg} /$ $100 \mathrm{ml}$ ). Reduction in the level of the other clotting factor with a long half-life in the circulation, namely factor II, was significantly correlated with the plasma fibrinogen levels obtained at the same time $(r=0.6$, $P<0.05$ ) (fig 3 ). Such reductions were only explicable on the basis of intravascular coagulation. However, the four patients with fibrin degradation products of above $8 \mu \mathrm{g} / \mathrm{ml}$ (the upper limit of normal for our laboratory is $2 \mu \mathrm{g} / \mathrm{ml}$ ) within $24 \mathrm{hr}$ of ingestion were not those with the lowest levels of factor II or fibrinogen.

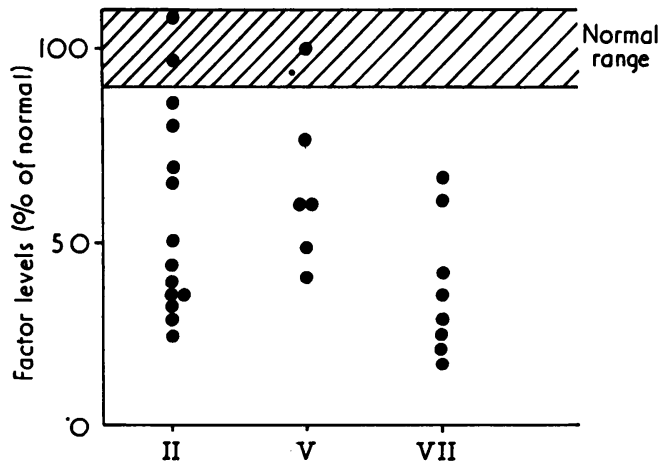

Fig 2 Levels of clotting factors $I I, V$ and VII expressed as a percentage of normal found within $24 \mathrm{hr}$ of the overdose. The normal range is shown by the shaded area. 


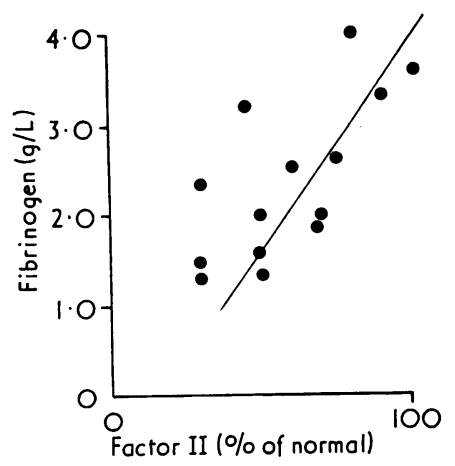

Fig 3 The correlation between factor II levels and plasma fibrinogen during the first $24 \mathrm{hr}$ of the overdose. The measurements were carried out on the same blood sample.

By $48 \mathrm{hr}$ of the overdose the levels of clotting factors II, V and VII were further reduced, but by $72 \mathrm{hr}$ the factor VII levels were returning towards normal, except in those who by this time had developed severe liver damage.

\section{CONTROLLED TRIAL OF FRESH FROZEN PLASMA}

At the time of randomization, the two groups of patients were similar with respect to prothrombin time ratio, age, and dose of paracetamol ingested (see table). The degree of ensuing hepatic damage was also similar in the two groups. The mean maximum serum bilirubin was greater in the control group but this difference was not significant statistically. Three patients in group B receiving fresh frozen plasma developed grades III or IV hepatic encephalopathy and one died, as compared with three patients with severe encephalopathy in the control group A, two of whom died.

The prothrombin time became more prolonged following admission to the trial in eight of the 10

\begin{tabular}{lcc}
\hline & \multicolumn{2}{l}{ Group } \\
\cline { 2 - 3 } & Controls & Treated with FFP \\
\hline $\begin{array}{l}\text { Age (yr) } \\
\begin{array}{l}\text { Paracetamol ingested } \\
\text { (estimated in g) }\end{array}\end{array}$ & $24(13)$ & $28(11)$ \\
$\begin{array}{l}\text { Mean prothrombin time ratio } \\
\text { at start of trial }\end{array}$ & $4 \cdot 0$ & $40(25)$ \\
$\begin{array}{l}\text { Maximum serum bilirubin } \\
(\mu \text { mol/l) }\end{array}$ & $103(50)$ & $3 \cdot 5$ \\
$\begin{array}{l}\text { Maximum aspartate amino- } \\
\text { transferase (iu/l) }\end{array}$ & $>1000$ & $79(18)$ \\
\hline
\end{tabular}

Table Comparison of clinical and biochemical data in the two groups

${ }^{1}$ Mean values with SD

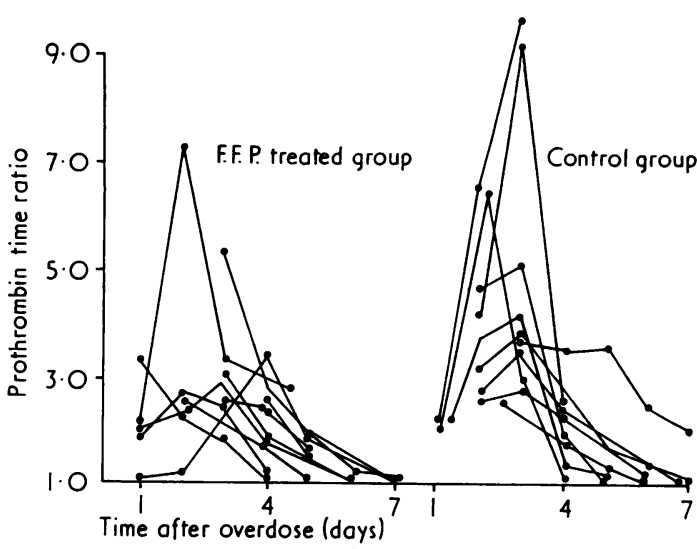

Fig 4 The prothrombin time ratio measured daily in the two groups of patients.

patients in group A, whereas in the group B cases, with one exception, it improved rapidly with administration of FFP (fig 4). Two of the patients in group A had to be given FFP when the pro-

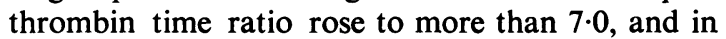
both the ratio was reduced to less than 3.5 within two hours of the infusion.

Comparison of the prothrombin time ratio at three days following the paracetamol overdose in the two groups showed that it was significantly lower in the FFP-treated patients $(\mathrm{u}=5.5, \mathrm{P}<0.05)$. Thus, only two in group B had a prothrombin time ratio of more than 3.5 at this time as compared with seven in group A. Nevertheless, it is to be noted that the prothrombin time ratio had returned to normal within a week in seven of the eight surviving patients in the control group $\mathrm{A}$, as well as in the nine patients recovering in the treated group $B$. None of the patients in either group showed clinical or haematological evidence of bleeding at any time.

\section{Discussion}

The changes in coagulation tests and factor levels were seen very soon after the paracetamol overdose, although the peak abnormalities in liver function tests are often not observed until the third or fourth day (Clark, Thompson, Borirakchanyavat, Widdop, Davidson, Goulding, and Williams, 1973a). A similar early prolongation of the prothrombin time has been reported following phosphorus ingestion (Marin, Montoya, Sierra, and Senior, 1971). These early changes may be a useful way of identifying those patients who need to stay in hospital, as all the patients who developed severe hepatic damage had a marked prolongation of the prothrombin time within $30 \mathrm{hr}$ of ingestion, while those with a 
normal prothrombin time ratio did not develop liver failure.

The results of individual clotting factor assays at this early stage were indicative of both impairment of hepatic synthesis together with intravascular coagulation. A reduction in factor V and VII levels within $24 \mathrm{hr}$ could be due to a failure of synthesis alone, as the half-lives are respectively 24 and five $\mathrm{hr}$ (Rizza, 1972). However, factor II has a half-life of three to four days, and early reduction in the levels could only be explained by the occurrence of intravascular coagulation. Evidence in favour of this was a close correlation between factor II levels and those of plasma fibrinogen. Whether the microthrombi found with intravascular coagulation could be important in the progression of hepatic damage by blocking the sinusoids and causing ischaemia is uncertain in man. However, rats given large doses of paracetamol have lesions in the liver which resemble infarcts (Gazzard, Hughes, Portmann, Dordoni, and Williams, 1974b), and accumulation of radioactive fibrinogen within the liver indicative of intravascular coagulation has been demonstrated in the rat within $14 \mathrm{hr}$ of the administration of carbon tetrachloride (Rake, Flute, Pannell, Shilkin, and Williams, 1973).

The exact roles of the synthetic defect, intravascular coagulation, and the mucosal erosions which are often present at necropsy in the pathogenesis of bleeding in these patients are quite unknown. In a recent controlled trial, continuous intravenous infusion of heparin to patients after a paracetamol overdose failed to affect the frequency of bleeding or the rate of recovery of the coagulation disturbance (Gazzard, Clark, Borirakchanyavat, and Williams, 1974a). In the present series, the administration of fresh frozen plasma did produce a rapid fall in the prothrombin time, but the coagulation disturbance was of short duration and the prothrombin time was normal within one week, even when replacement therapy was not given.

The use of FFP represents a considerable load of salt and water which could be harmful to patients whose renal excretion of sodium may be inappropriately low (Wilkinson, Blendis, and Williams, 1973). This fluid load may contribute to pulmonary and cerebral oedema, which develop in a proportion of these patients. This problem could be circumvented by the use of a concentrate of clotting factors which provides large amounts of clotting factors II, IX and $X$ in a small volume of fluid. However, in a recent trial of such a concentrate (Gazzard, Lewis, Ash, Bidwell, Rizza, and Williams, 1974c) both bleeding and evidence of severe intravascular coagulation were produced, possibly because the preparation contained small amounts of activated clotting factor which were not cleared by the damaged liver. At present, however, it would seem reasonable to continue to use fresh frozen plasma in these patients, but only when a severe and persistent coagulation defect appears, for instance, with an increased prothrombin time ratio of more than 7.0 for two days or more. As factor VII has such a short half-life, the FFP should probably be administered every three hours rather than by our previous six hourly regime.

We are indebted to Dr M L Lewis and the Haematology Department of King's College Hospital for their continued cooperation. BGG was supported by the King's College Hospital Research Committee and JMH by Serological Products Ltd.

\section{References}

Clark, R., Thompson, R. P. H., Borirakchanyavat, V., Widdop, B., Davidson, A. R., Goulding, R., and Williams, R. (1973a). Hepatic damage and death from overdose of paracetamol. Lancet, 1, 66-70.

Clark, R., Borirakchanyavat, V., Gazzard, B. G., Rake, M. O., Shilkin, K. B., Flute, P. T., and Williams, R. (1973b). Disordered hemostasis in liver damage from paracetamol overdose. Gastroenterology, 65, 788-795.

Denson, K. W. E. (1972). In Human Blood Coagulation, Haemostasis and Thrombosis, edited by R. Biggs, pp. 587-675. Blackwell, Oxford.

Gazzard, B. G., Clark, R., Borirakchanyavat, V., and Williams, R. (1974a). A controlled trial of heparin therapy in the coagulation defect of paracetamol-induced hepatic necrosis. Gut, 15, 89-93.

Gazzard, B. G., Hughes, R., Portmann, B., Dordoni, B., and Williams, R. (1974b). Protection of rats against the hepatotoxic effects of paracetamol. Brit. J. exp. Path., 55, 601-605.

Gazzard, B. G., Lewis, M. L., Ash, G., Bidwell, E., Rizza, C. R., and Williams, R. (1974c). Coagulation factor concentrate in the treatment of the haemorrhagic diathesis of fulminant hepatic failure. Gut, 15, 993-998.

Marin, G. A., Montoya, C. A., Sierra, J. L., and Senior, J. R. (1971) Evaluation of corticosteroid and exchange transfusion treatment of acute yellow-phosphorus intoxication. New Engl. J. Med., 284, 125-134.

Merskey, C., Lalezari, P., and Johnson, A. J. (1969). A rapid, simple, sensitive method for measuring fibrinolytic split products in human serum. Proc. Soc. exp. Biol. (N. Y.), 131, 871-875.

Prescott, L. F., Wright, N., Roscoe, P., and Brown, S. S. (1971) Plasma-paracetamol half-life and hepatic necrosis in patients with paracetamol overdosage. Lancet, 1, 519-522.

Rake, M. O., Flute, P. T., Shilkin, K. B., Lewis, M. L., Winch, J. and Williams, R. (1971). Early and intensive therapy of intravascular coagulation in acute hepatic failure. Lancet, 2 , 1215-1218.

Rake, M. O., Flute, P. T., Pannell, G., Shilkin, K. B., and Williams, R. (1973). Experimental hepatic necrosis: studies on coagulation abnormalities, plasma clearance and organ distribution of ${ }^{125}$ I-labelled fibrinogen. Gut, 14, 574-580.

Rizza, C. R. (1972). In Human Blood Coagulation, Haemostasis and Thrombosis, edited by R. Biggs, pp. 334. Blackwell, Oxford.

Wilkinson, S. P., Blendis, L. M., and Williams, R. (1974). Frequency and type of renal and electrolyte disorders in fulminant henatic failure. Brit. med. J., 1, 186-189. 